\title{
Does steric interference between splice sites block the splicing of a short c-src neuron-specific exon in non-neuronal cells?
}

\author{
Douglas L. Black \\ The Whitehead Institute for Biomedical Research, Cambridge, Massachusetts 02142 USA
}

\begin{abstract}
The neuron-specific splicing of the mouse c-src N1 exon was analyzed. Model src genes, transiently expressed in HeLa and LA-N-5 neuroblastoma cells, were assayed for the insertion of the 18-nucleotide neuron-specific N1 exon into their product mRNA. The normal clone fails to use this exon in HeLa cells but inserts the exon into $50 \%$ of the mature mRNA in LA-N-5 cells. When the exon and flanking intron sequences are placed between two adenovirus exons, the $\mathrm{N} 1$ exon is still only inserted in the neural cells. Thus, the neural specificity is a property of the exon itself and its immediate flanking sequences. Simply extending the length of the N1 exon to 109 nucleotides allows its efficient use in HeLa cells, implying that the exon is normally skipped because it is too short to allow spliceosomes to assemble at both ends simultaneously. This model predicts that exclusion of the exon should be sensitive to proteins or mutations that alter the relative strength of the flanking splice sites. Mutations that change these splice sites support this hypothesis.
\end{abstract}

[Key Words: Pre-mRNA splicing; alternative splicing; neurons; c-src; neural src; spliceosomes]

Received November 7, 1990; revised version accepted January 10, 1991.

The splicing of pre-mRNA is an important point of control in the regulation of eukaryotic gene expression. The primary transcript from a gene is often differentially processed to generate multiple mRNAs whose protein products have different biological activities. These alternative patterns of splicing can be very complex and may involve optional exons, optional introns, or the shifting in the position of single splice junctions. The choice of splicing pattern is frequently regulated and can vary with tissue type, developmental stage, or sex. Although many examples of regulated splicing have been described, little is known about the mechanisms that underlie this phenomenon (for review, see Smith et al. 1989a).

Through in vitro reconstitution studies much has been learned about the general biochemistry of splicing (for review, see Krainer and Maniatis 1988). Intron removal is a two-step process involving first a cleavage at the $5^{\prime}$ splice junction with a concomitant religation of the $5^{\prime}$ end of the intron to the 2 ' hydroxyl of a specific adenosine residue within the intron. This $A$ residue, within a sequence known as the branchpoint, is usually found 18-35 nucleotides upstream from the $3^{\prime}$ splice site. The second step of the reaction is the cleavage at the $3^{\prime}$ splice site and ligation of the two exons. These reactions are carried out by a large catalytic complex called the spliceosome.

The spliceosome assembles onto the pre-mRNA and is made up of a set of four small nuclear ribonucleoproteins
(snRNPs), named U1, U2, U4/U6, and U5, as well as additional proteins (Guthrie and Patterson 1988; Steitz et al. 1988). The U1 and U2 snRNPs bind to the premRNA at the $5^{\prime}$ splice site and branchpoint, respectively, via RNA : RNA base-pairing. Some of the protein factors may act to stabilize these snRNP-substrate interactions. Several proteins have been identified in splicing extracts that bind the polypyrimidine stretch upstream from the $3^{\prime}$ splice site /Gerke and Steitz 1986; Tazi et al. 1986; Ruskin et al. 1988; Swanson and Dreyfuss 1988; Garcia-Blanco et al. 1989). One of these proteins, $\mathrm{U} 2 \mathrm{AF}$, is required for $\mathrm{U} 2$ binding to the branchpoint and for splicing activity in vitro (Zamore and Green 1989/. Other factors affect the choice of 5' splice sites used in vitro and in vivo (Ge and Manley 1990; Krainer et al. 1990). An initial step in the pathway of spliceosome assembly appears to be the formation of a U1/U2 complex, involving both $5^{\prime}$ splice site and branchpoint sequences (Konarska and Sharp 1987; Lamond et al. 1987; Zillmann et al. 1987; Ruby and Abelson 1988; Seraphin and Rosbash 1989). It is during the formation of this complex or at the earlier initial binding of the U1 or U2 snRNPs that the choice of splice sites is likely to be regulated.

How even constitutively used splice sites are chosen is still a mystery. Branchpoints and $5^{\prime}$ and $3^{\prime}$ splice sites adhere to definable consensus sequences, and complementarity to $\mathrm{U} 2$ and $\mathrm{U} 1$ snRNAs is critical to the func- 
tion of the first two (Zhuang and Weiner 1986, 1989; Parker et al. 1987; Seraphin et al. 1988; Siliciano and Guthrie 1988; Wu and Manley 1989|. However, there are many cryptic splice sites that also match the consensus sequences but are not used unless the normal site is mutated (Treisman et al. 1983). The properties that determine the correct site are poorly understood, although the sequence around the splice site can affect its utilization. For example, the proximity of exon sequence can affect the choice of which of two duplicated splice sites is used in vitro (Reed and Maniatis 1986). Moreover, multiple 5' splice sites in a region can interfere with each other, preventing splicing at any site (Nelson and Green 1988). Because U1 binds to most sequences that fit the 5 ' splice site consensus sequence, other factors must determine whether this interaction will be functional (Chabot and Steitz 1987b; Nelson and Green 1988).

In Drosophila, several factors have been identified that regulate the alternative splicing patterns of specific transcripts (Baker 1989). Although it is not known how these proteins interact with the general splicing machinery, one of them, the product of the Sex lethal gene, can bind directly to a target sequence in the transcripts it regulates (Inoue et al. 1990). This sequence appears in the polypyrimidine stretch of 3 ' splice junctions that are skipped in the presence of the Sex lethal protein. These data led to a simple splice site blockage model for splicing regulation by Sex lethal (Sosnowski et al. 1989). Besides the Sex lethal target, very few cis-acting elements that regulate splicing have been well defined. Mutational analysis of various genes has shown that exon sequences (Somasekhar and Mertz 1985; Mardon et al. 1987; Helfman et al. 1988; Cooper and Ordahl 1989; Hampson et al. 1989; Laski and Rubin 1989; Streuli and Saito 1989; Nagoshi and Baker 1990), intron sequences (Laski and Rubin 1989; Helfman et al. 1990|, and splice junction sequences themselves (Emeson et al. 1989; Gallego and Nadal-Ginard 1990; Nasim et al. 1990) can all affect the regulation of different splicing patterns. These studies led to the conclusion that there are multiple mechanisms for the regulation of splicing, many of which may be more complex than the Sex lethal model.

The c-src gene encodes a $60-\mathrm{kD}$ protein tyrosine $\mathrm{ki}$ nase (Bishop and Varmus 1985; Pawson 1988). c-src is well known for its ability in mutant form (such as the $v$-src gene encoded by Rous sarcoma virus/ to induce the oncogenic transformation of cells. c-src is expressed in a wide variety of cell types in which the pre-mRNA is subject to the same splicing pattern. In some neurons, however, the splicing pattern is different. In these cells, a new 18-nucleotide exon ( $\mathrm{Nl})$ is inserted between the constitutive src exons 3 and 4 producing a neural-specific protein, n-src (Levy et al. 1987; Martinez et al. 1987). Recently, another neural-specific src exon (N2) has been found; this exon is inserted between exons $\mathrm{N} 1$ and 4 in some src mRNAs found in the human brain (Pyper and Bolen 1990). The extra amino acids encoded by the $\mathrm{N} 1$ and $\mathrm{N} 2$ exons fall in the middle of a conserved domain of the protein called the src homology region 3. Mutations in this region can induce the transforming ability of the protein, and the domain may also mediate actin binding (Drubin et al. 1990). How the insertion of the neural-specific exons affects the activities of src and why the use of these exons is so precisely regulated is not clear.

I have set out to develop the mouse c-src gene as a simple model system for studying a regulated splicing event. In this study, I sought to define the cis-acting elements that are necessary for regulating the inclusion of the N1 exon. Using a transient-transfection assay, I find that all sequences needed for regulated insertion are within either the N1 exon itself or the sequences immediately flanking it. Neither splice junction is rigidly neural specific. Rather, exclusion of the exon in non-neuronal cells seems to be due to steric problems associated with its short length. This mode of repression has implications for the activation of the exon in neurons and for the splicing of short exons in general.

\section{Results}

\section{The genomic location of the N1 exon}

A genomic clone of a portion of the mouse src locus (the gift of Dr. Ricardo Martinez) was extensively restriction mapped and subcloned (Fig. la). The N1 exon is separated from exon 3 by $208 \mathrm{bp}$ and from exon 4 by $\sim 3.5 \mathrm{~kb}$. The location of the $\mathrm{N} 2$ exon has not been determined, and I have focused exclusively on the $\mathrm{Nl}$ exon.

The sequence of the region surrounding the Nl exon was determined from the mouse and from a clone of the chicken src locus (provided by Dr. Lu-Hai Wang (Wang et al. 1987); Fig. lb]. The intron upstream of N1 is larger in the chicken (345 nucleotides) and has little sequence conservation with the mouse intron except at the splice junctions. Similarly, the sequence immediately downstream from exon $\mathrm{N} 1$ had no obvious similarities between mouse and chicken, though short common sequences can be found by computer analysis. The splice junctions all conformed to the established consensus sequences extremely well (Shapiro and Senapathy 1987). The exon 3 splice donor (CAC/GTGAGT) and the exon Nl donor (CAG/GTGTGT) each have an 8 of 9 match to the consensus and each are identical in mouse and chicken. The splice acceptor sequences for exons $\mathrm{Nl}$ and 4 are not conserved between mouse and chicken, but all match the consensus sequence well.

\section{Cell lines that express $n$-src}

To study the regulation of the $\mathrm{N} 1$ exon I needed cell lines that expressed each of the spliced forms of the message. Using RNase protection and polymerase chain reaction (PCR) assays, I measured the endogenous levels of the two forms of src mRNA (called c-src and n-src) in a series of mammalian cell lines. $\mathrm{N}$-src transcripts were found only in cells of neuroendocrine origin but not in all cells of this type. Using a PCR-based assay (Fig. 2), two cell lines are seen to make almost exclusively c-src: mouse NIH-3T3 cells (lane 3) and human HeLa cells (lane 4), 
a

$1 \mathrm{~kb}$

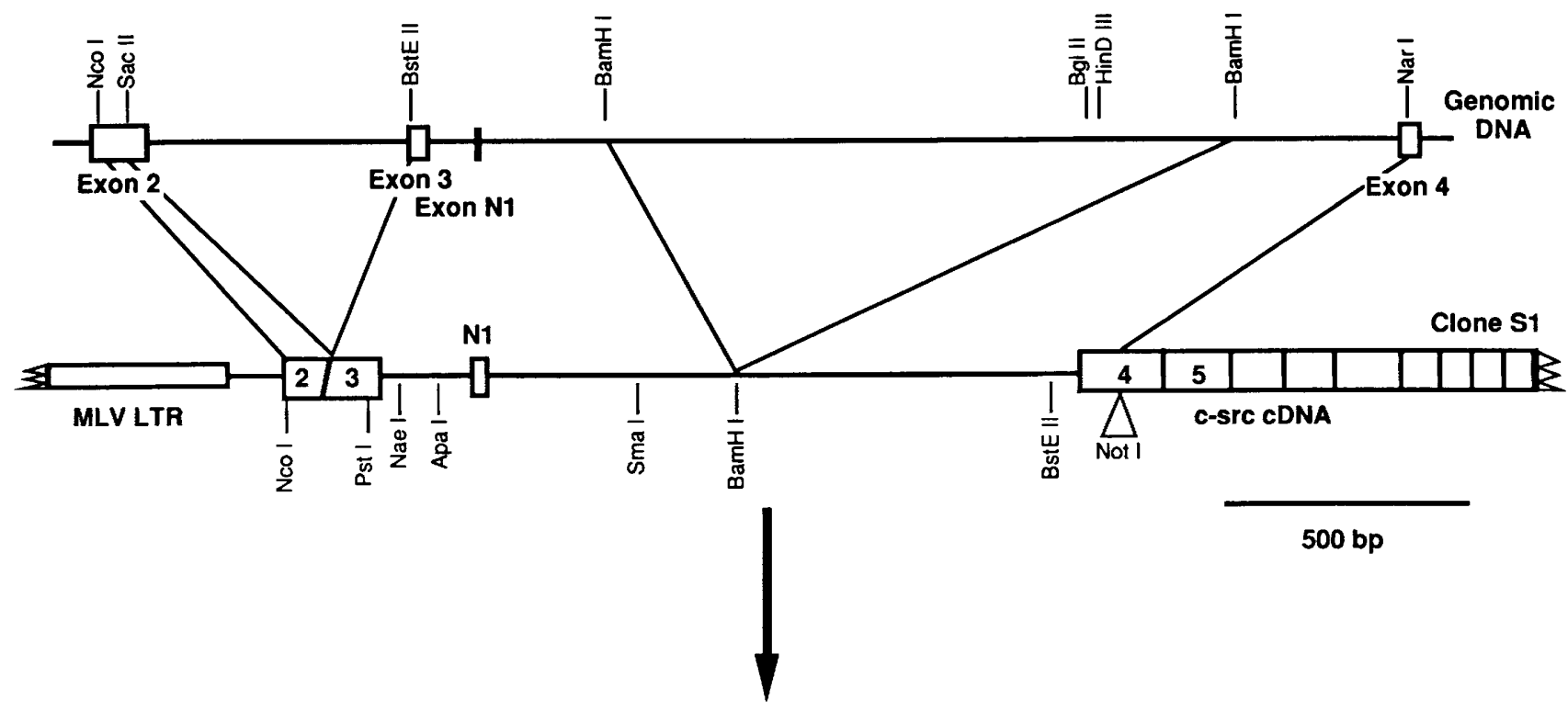

$3 \mathbf{N 1}$

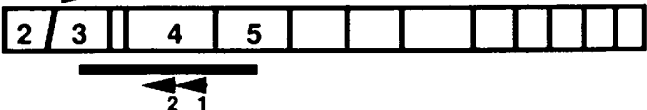

N-SRC

\section{$2 / 1$}

\begin{tabular}{|l|l|l}
\hline 3 & 4 & \\
\hline
\end{tabular}

b'

101 NaP I
TGCCOGCAGAGGGCGGTGCAGAGCCTACAGGGCTGCTICTGCTCTTGGTGGGTGGCGGCCCTCCCTAGACCCCAACCAGTATCCTCCCITGTCCTGGGCC:

201 CTGTCITCGCACCTCAGCCTCTCCTTCTCTCTCCTTCICTCTCOCTGGCCCTIAGGSEON N CTCAGCIICTCTCCTGACTGTITITICTCTCTOCATGCCATGCTITCATGTAGGAGAAAAGTGGACGTCAGGTGTTATIGCOGGTTACGATTACTGT $30 !$

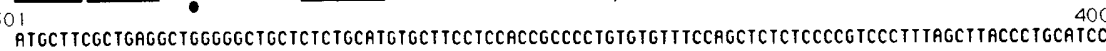

chicken 40 1 SOC
CACCTGTATGAGCCGACCCTCCATCTTCTCCCCACACCTTCCTOTTAGCTCTCTICCTCCCTGTTCTGATTIOTGATTCCACATTGGGTGCCAGCTACAT 50

SO1 600

GCAGGACCCAGIGTATICTGTAGGCCAGGGAGGGAGGCAGTGTGGTGGGGRGTGGUTACACCAGACCAGGTCAGGGGTGGATAGAAGCAGGCCGGGGIC nOUSE

601 SMa 1619

1 BSt E:11 80

GGTIACEGACCCEGATCCCCCGTGACCTCATICTTTGCTCCCTCCCTCCTGCTCRGAGAGGGRGACTGGTGGCTGGCACA CCGGGGTGCTGTGGGCTCTTIGGCTTCACACTGAGTGTITTTGGTTCTCTTGCAGBEARGGTGACTGGTG

nouse

nouse

mouse

nouse

nouse

Figure 1. (a) Maps of the mouse $s r c$ locus and the $s r c$ minigene S1. The upper horizontal line is the $s r c$ locus from the mouse from exon 2 to exon 4 . The exons are represented by boxes and the introns by a line. The approximate scale is given by the $1-\mathrm{kb}$ bar. The restriction sites indicated are not necessarily unique. The second horizontal line is the $S I C$ minigene S1. The fragments derived from the genomic clone are indicated by the lines to the genomic map. The murine leukemia virus LTR and the $s r c$ cDNA, which derive from the clone pVN1.8, are also labeled. The scale for the S1 clone is indicated by the 500-bp bar. The second intron in S1 has a large BamHI fragment $(\sim 2.5 \mathrm{~kb})$ removed from it. The NotI site is derived from an inserted linker. The distance from the start of transcription to the $5^{\prime}$ end of exon 2 is $\sim 700 \mathrm{bp}$. The distance from the end of the cDNA insert to the polyadenylation site is $\sim 650 \mathrm{bp}$. Below S1 the two spliced mRNAs are diagramed, either skipping (c-src) or inserting (n-src) exon N1. The horizontal bars below each mRNA denote the RNase protection product generated by that mRNA. The arrowheads indicate the oligonucleotide primers used for the PCR assay (see Materials and methods). (b) Sequences surrounding the mouse and chicken N1 exons. The mouse sequence runs from the middle of exon 3 to the first SmaI site downstream of exon N1. Also shown are the 80 nucleotides surrounding the mouse exon 4 splice acceptor. The chicken sequences surrounding splice junctions from exons $3, \mathrm{~N} 1$, and 4 are also shown. These are aligned with the mouse splice junctions and shown on the line below. Exon/intron boundaries are shown by vertical lines. Sequences in common between the $\mathrm{N} 1$ exon splice acceptors from the mouse and the chicken are overlined in the mouse and underlined in the chicken sequence. Putative branchpoints for $\mathrm{Nl}$ exon splice acceptor are indicated (O). Selected restriction sites in the mouse sequence are also indicated. These sequences have been submitted to GenBank (accession nos. M61221, M61222, M61223, M61224, and M61225). 


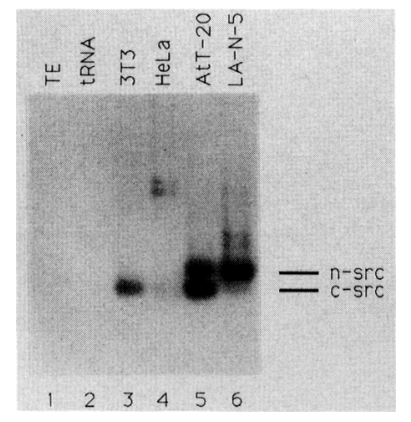

Figure 2. PCR assay of endogenous c-src and n-src mRNA in cell lines. Total cytoplasmic RNA from various cell lines was assayed for endogenous c-src and n-src mRNA by a PCR assay. This assay involves making cDNA from a sample of mRNA using a $s r c$-specific primer downstream from the alternative exon. The cDNA is then amplified by PCR using primers upstream and downstream from the Nl exon (see Fig. la). This produces a long amplification product from the n-src mRNA and a shorter product from the c-src mRNA. These PCR products were analyzed by gel electrophoresis to measure the ratio of the two splice variants. The reactions contained a small amount of $\left[\alpha{ }^{32} \mathrm{P}\right] \mathrm{dCTP}$ to allow visualization by autoradiography. The products from the $\mathrm{n}$-src and c-src message are indicated at right. The PCR reaction in lane 1 was run on a sample of buffer alone. The PCR reactions in lanes $2-6$ were run on reverse transcription reaction mixtures containing tRNA (lane 2); 3 T3 cell RNA (lane 3); HeLa cell RNA (lane 4); AtT-20 cell RNA (lane 5); LA-N-5 cell RNA (lane 6). The upper bands in the HeLa lane are of unknown origin.

which contain very little src mRNA but make c-src. The mouse pituitary cell line AtT-20 (lane 5) includes the N1 exon in $\sim 30-40 \%$ of its $s r c$ mRNA. The human neuroblastoma line LA-N-5 (lane 6) has been reported previously to make the n-src protein (Yang and Walter 1988) and this is confirmed with $>90 \%$ of the $s r c$ mRNA containing the $\mathrm{Nl}$ exon. These cell lines and others were also assayed for $s r c$ splicing by RNase protection with similar results (data not shown), indicating that the ratio of the two product bands has not been skewed by the PCR amplification process and also that the upper bands in the HeLa lane are not derived from src m-RNA. Another well-studied neural-specific splicing event, in the calcitonin/CGRP gene, occurs efficiently in the embryonal carcinoma cell line F9 (Emeson et al. 1989). As these cells make little or no n-src (data not shown), these two neural-specific splicing patterns are likely to be regulated by different factors. The HeLa and LA-N-5 lines were used for all subsequent experiments presented here.

\section{Deletion analysis of a src minigene}

To analyze the cis-acting elements that regulate the use of the Nl exon, I constructed a src minigene by fusing portions of the mouse genomic clone to the src cDNA. The $S 1$ construct (Fig. 1a) contains a portion of $s r c$ exon 2 fused to a fragment of the genomic DNA starting in exon 3 and proceeding through exon $\mathrm{Nl}$ and its flanking introns and into exon 4 where it is joined to the src cDNA. This modified $s r c$ gene was inserted between the two long terminal repeats (LTRs) of the Moloney murine leukemia virus in the plasmid pVN1.8 (Martinez et al. 1987) to provide the promoter/enhancer functions and a polyadenylation site for expressing the gene in cells. After transient expression in HeLa and LA-N-5 cells, splicing of $\mathrm{S} 1$ gene transcripts was analyzed by RNase protection (Fig. 3b). HeLa cells produced almost exclusively the shorter c-src-protected product indicating the skipping of the N1 exon (Fig. 3b, lane 5). The LA-N-5 cells, however, inserted the $\mathrm{N} 1$ exon in $\sim 50 \%$ of the mature transcripts from the transfected gene producing a larger protected fragment (Fig. 3b, lane 11). This is somewhat less than the $90 \% \mathrm{n}$-src seen from the endogenous gene and can fluctuate between different transfections from $30 \%$ to $60 \%$.

Because the S1 clone maintained the neural-specific insertion of the $\mathrm{Nl}$ exon, this clone was further modified to test the effects of mutations on the control of the splicing of the exon (Fig. 3a,b). In the S2 clone, 5 nucleotides were inserted into the $\mathrm{Nl}$ exon to create a ClaI site, increasing the size of the exon from 18 to 23 nucleotides. The insertion had no effect on the regulation of the splicing; S2 produced only c-src transcripts in HeLa cells (Fig. 3b, lane 6) and both c-src and n-src in LA-N-5 cells (lane 12). Note that transcripts from this clone and all clones made from it generated a new $\mathrm{n}$-src-derived band due to partial clipping of the probe at the ClaI insertion site.

Deletion mutations in the two introns also had little effect on the use of the N1 exon. Removing 96 nucleotides from the 208-nucleotide first intron (clone S3; Fig. $3 \mathrm{~b}$, lanes 9 and 15), deleting another $\sim 1000$ nucleotides from the already shortened second intron $(\mathrm{S} 4$, lanes 7 and 13), or deleting from 141 nucleotides downstream from the $\mathrm{N} 1$ exon to the BamHI site farther downstream (S5, lanes 8 and 14) all had similar results. These clones still produced only c-src in HeLa cells and both c-src and $\mathrm{n}$-src $(39-57 \%)$ in LA-N-5 cells. The S4 deletion did eliminate an LA-N-5-specific band of unknown origin ( $X$; see Fig. 3b, cf. lane 13 with lanes $11,12,14$, and 15 ). This band may be derived from exon N2 or another unidentified exon that is now deleted in S4.

\section{The N1 exon is still regulated with heterologous flanking exons}

The S3 and S5 mutants deleted intron sequence to 55 nucleotides upstream and 141 nucleotides downstream of the N1 exon without affecting its splicing. To test whether the flanking src exons 3 and 4 were required for regulating the use of $\mathrm{N} 1$, the $\mathrm{A} 4$ construct was made (Fig. 4a). This contained the N1 exon and its immediate flanking sequences (from nucleotide 104 to nucleotide 616 in Fig. $1 \mathrm{~b}$ ) inserted into the adenovirus major late transcription unit replacing the adenovirus leader exon 2. This clone was expressed from the vector pEVRF-1 containing the cytomegalovirus $(\mathrm{CMV})$ promoter/enhancer. After 

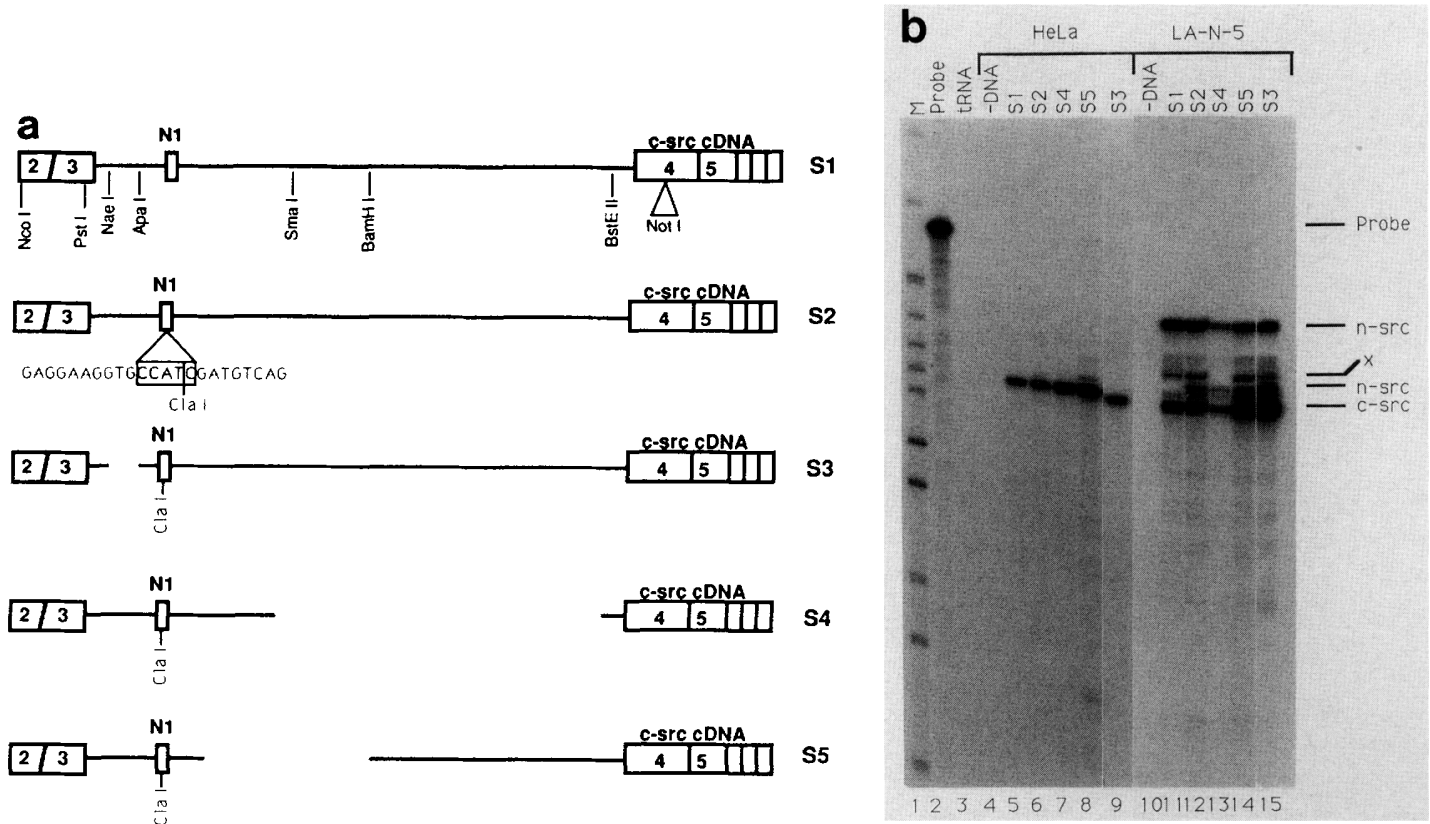

Figure 3. (a) Maps of wild-type and modified src minigenes. Clone $\mathrm{S} 1$ is diagramed at the top (as in Fig. 1). The boxes indicate exons and the lines introns. Clone S2 contains a 5-nucleotide insertion to form a ClaI site. The inserted nucleotides are boxed, and the ClaI site is indicated by a vertical line. Clones S3, S4, and S5 contain deletions in the introns indicated by the gaps in the horizontal line. S3 is deleted from the NaeI site to the ApaI site in intron 1 (nucleotides 105-201 in Fig. 1b). S4 is deleted from the SmaI site at nucleotide 616 to the BstEII site 55 bp upstream of exon 4. S5 is deleted from 141 bp downstream of exon N1 to the BamHI site $\sim 700$ bp upstream of exon 4. (b) RNase protection assays of mutant src gene transcripts. HeLa and LA-N-5 cells were transfected with various clones, and after transient expression, RNA was isolated from the cells and subjected to RNase protection analysis. The RNase protection probe was derived from the mouse $\mathrm{n}-s \mathrm{~s} c \mathrm{cDNA}$ and is complementary to exons $\mathrm{Nl}$ and 4 and to portions of exons 3 and 5 (see diagram in Fig. la). The mouse probe does not detect the endogenous human src transcripts. The probe also contained the NotI linker inserted at the NarI site in exon 4. (Lane 1) Marker DNA; (lane 2) undigested RNA probe; (lane 3) an RNase reaction run with tRNA. (Lanes 4-9) RNA from HeLa cells after transfection with various DNAs; (lanes 10-15) similar samples of LA-N-5 cell RNA. The clones transfected were no DNA (lanes 4 and 10); S1 (lanes 5 and 11); S2 (lanes 6 and 12); S4 (lanes 7 and 13); S5 (lanes 8 and 14); S3 (lanes 9 and 15). The different bands are identified at right. The lower $\mathrm{n}$-src band is produced by the ClaI site in S2 and the clones derived from it. Band $\mathrm{X}$ is not seen in clones that are missing the BamHI-BstEII fragment in intron 2 (clone S4 and its derivatives).

transient expression in HeLa and LA-N-5 cells, the splicing of these constructs was assayed by the PCR assay (Fig. 4b). In transcripts from clone $\mathrm{A} 4$, the $\mathrm{N} 1$ exon was still inserted into the mRNA only in LA-N-5 cells and not in HeLa. HeLa cells produced the exon 1-3 splice (cf. lane 7 with lane 9) and LA-N-5 cells produced an additional transcript $(\sim 10 \%$ of the total), where $\mathrm{N} 1$ is inserted between exons 1 and 3 (lane 8). Two other constructs were tested with the same $\mathrm{Nl}$ exon fragment between adenovirus exons 1 and 2 or exons 2 and 3 . In these clones, too, the $\mathrm{Nl}$ exon was inserted between its two flanking exons only in LA-N-5 cells and not in HeLa cells (data not shown). Thus, the Nl exon maintains its neural specificity regardless of its flanking exons.

To determine whether either $\mathrm{Nl}$ splice junction could only function in neurons, two constructs containing hybrid exons were tested (Fig. 4a). These fused the $5^{\prime}$ portion (16 nucleotides) of the $\mathrm{N} 1$ exon with its splice acceptor to the $3^{\prime}$ portion ( 37 nucleotides) of the adenovirus leader exon 2 (clone A5) or the $3^{\prime}$ portion $(9$ nucleotides) of N1 with its splice donor to the $5^{\prime}$ portion (43 nucleotides) of adenovirus exon 2 (clone A6). If the N1 exon worked in a similar manner to the Sex lethal gene of Drosophila and contained a sequence in one of its splice junctions that determined its neural specificity, then one of these hybrid exons should only be inserted in LA-N-5 cells. This was not the case, as both hybrid exons were used constitutively (Fig. 4b). In HeLa (lanes 11 and 13 ) and in LA-N-5 cells (lanes 12 and 14) the hybrid exons were always included in the mRNA, producing little or no transcript where exon 1 is spliced to exon 3 (cf. lanes 9 and 10 with lanes 11-14). This result indicated that each splice junction alone can function perfectly well in HeLa cells, but in combination their use is prevented.

Increasing the length of the N1 exon allows its use in non-neural cells

The implication of the hybrid exon results was that the two halves of $\mathrm{Nl}$ in some way combine to repress inclusion of the exon in HeLa cells. Because the Nl exon is so short (23 nucleotides with the ClaI insertion), its exclusion could be due to the inability of splicing complexes to form on both ends simultaneously. To test this hypothesis, several small DNA fragments (85-86 nucle- 
a

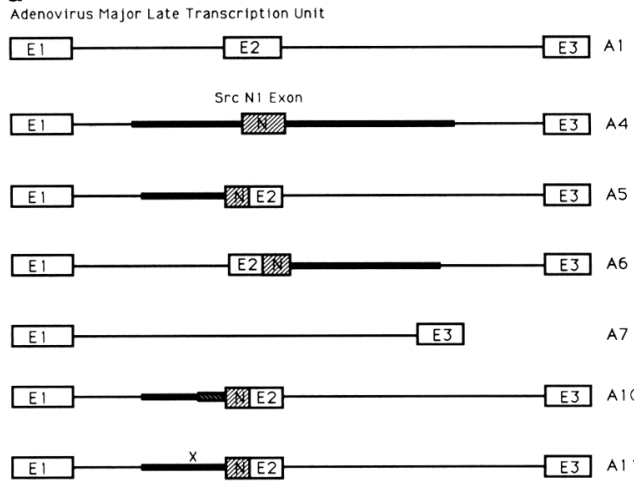

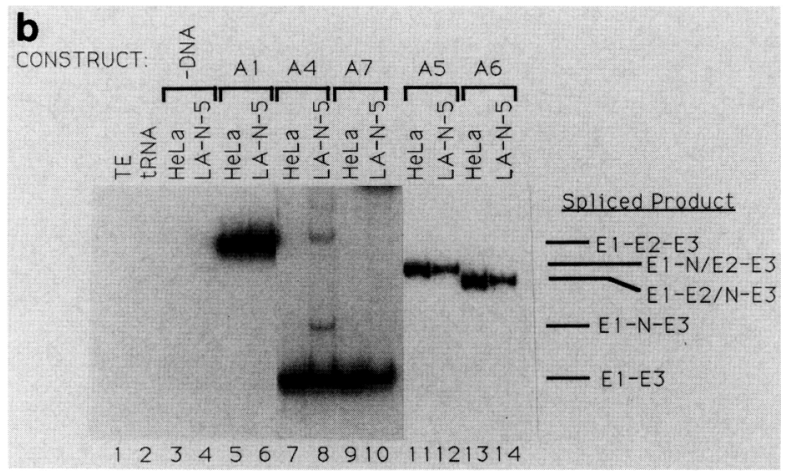

Figure 4. (a) Adenovirus/src hybrid genes. The A series of clones is diagramed. The adenovirus exons are open boxes; the src exon is a stippled box. The adenovirus intron sequence is indicated by the narrow line; the src intron by the thicker line. The mutant splice acceptors in clones A10 and A11 are indicated by the thick stippled line and the X. The adenovirus exon 1 is joined at the $P_{V u I I}$ site to the leader sequence of the pEVRF1 vector $143 \mathrm{bp}$ downstream from the transcription start site of the CMV promoter. The third adenovirus exon is joined at the $X$ hol site to the pEVRF1 trailer sequence $\sim 800$-bp upstream of the rabbit $\beta$-globin polyadenylation site. This trailer sequence also contains a 573-nucleotide globin intron. In clone A4, the intron upstream of $\mathrm{N} 1$ contains 89 nucleotides of adenovirus sequence and 151 nucleotides of $s r c$ sequence. The intron downstream of N1 contains 342 nucleotides of src sequence followed by 153 nucleotides of adenovirus sequence. The adenovirus sequence in clone Al contains several modifications, described in Materials and methods. (b) PCR assay of the adenovirus/src hybrid genes. The PCR assay was performed on mRNA produced from the different clones after transfection into HeLa or LA-N-5 cells. The assay was similar to that in Fig. 2 except that the primers derived from adenovirus and pEVRF1 sequences (see Materials and methods). The product ratios of this PCR assay were verified by primer extension assays. (Lanes 1 and 2) PCR reactions run on buffer alone or a reverse transcription reaction of tRNA, respectively. (Lanes $3,5,7,9,11$, and 13) Assays of clones transfected into HeLa cells. (Lanes 4, 6, 8, 10, 12, and 14) Transfections into LA-N-5 cells. The transfections were with no DNA (lanes 3 and 4), clone A1 (lanes 5 and 6), A4 (lanes 7 and 8), A7 (lanes 9 and 10), A5 (lanes 11 and 12), and A6 (lanes 13 and 14). The different spliced products are labeled at right. The upper band in lane 8 is believed to be a heteroduplex of the two spliced products.

otides) were inserted into the exon at the ClaI site (Fig. $5 \mathrm{a}$, clones $\mathrm{S} 7$ and $\mathrm{S} 8 \mathrm{1}$. All of the fragments had the same striking effect: The exon was now used with almost $100 \%$ efficiency in both HeLa cells (Fig. 5c, lanes 6 and 7 ) and LA-N-5 cells (Fig. 5d, lanes 3 and 4). Moreover, the sequence of the insert was irrelevant, as similar results were obtained using a $s r c$ exon fragment insert $[S 7$; Fig. $5 c$, lane 6), or an adenovirus intron fragment in forward (S8; Fig. 5c, lane 7) or reverse orientation (data not shown). These results indicate that while both splice junctions can function in HeLa cells, positioning the junctions close together precludes their use, perhaps by creating a steric block to splicing complex assembly.

\section{Splice iunction mutations in the N1 exon}

If the two $\mathrm{N} 1$ exon splice sites sterically interfere with each other, one expects that changing the strength of one site (and hopefully therefore the rate of factor binding to one side) would relieve the inhibition by upsetting the competition between the sites. To determine whether other splice acceptor sequences might also respond to

Figure 5. (a) Maps of mutant $s r c$ genes. Various mutations in the $s r c$ minigene are diagramed. Clones S7 and S8 have different insertions into the N1 exon. Clones S9-S15 have various point mutations in the splice junction sequences, indicated by Xs. Clones S16 and $\$ 17$ have new splice acceptor sequences indicated by the stippled boxes. The exact nucleotide sequences of these mutations are shown in $b$. As indicated, these clones have different DNA backbones. Clones S7, S8, S9, S12, S16, and S17 are derived from clone S2. Clones S10, S11, S13, and S15 are derived from clone S4. Clone S14 is derived from clone S5. (b) Sequences of various src mutants. The third line shows the sequence of the $\mathrm{S} 2$ clone flanking the $\mathrm{N} 1$ exon. This clone is normal except for the insertion to form the ClaI site, which is underlined. The N1 exon borders are indicated by the vertical lines. Lines 1 and 2 show the sequence of the same region in the S17 and S16 clones, respectively. The underlined sequence in clone S17 is from the src exon 4 splice acceptor. In clone S16, the added sequence is from the splice acceptor from the second exon of the adenovins major late transcription unit. The point mutations in clones S9 to S15 are shown below the S2 sequence. S9, S10, and S11 all have changes in the putative branchpoint. Clones S12 and S13 have alterations in the polypyrimidine stretch. Clone S14 has a mutant splice donor sequence, and S15 has a mutation downstream from this sequence. (c) Splicing of various src mutants expressed in HeLa cells. After expression in cells, the clones were assayed by RNase protection. (Lanes 1-3) As in Fig. 3b. The HeLa cells were transfected with no DNA (lane 4), S2 (lane 5), S7 (lane 6), S8 (lane 7), S9 (lane 8), S10 (lane 9), S11 (lane 10), S12 (lane 11), S13 (lane 12), S14 (lane 13), S15 (lane 14), S16 (lane 15), and S17 (lane 16). The different spliced products are labeled at right. (d) RNase protection assays of various src mutants expressed in LA-N-5 cells. As in $c$ the LA-N-5 cells were transfected with no DNA (lane 1), S2 (lane 2), S7 (lane 3), S8 (lane 4), S9 (lane 5), S10 (lane 6), S11 (lane 7), S12 (lane 8), S13 (lane 9), S14 (lane 10), S15 (lane 11), S16 (lane 12), and S17 (lane 13). Lanes 3 and 4 are from a gel that was run slightly longer than the other lanes. Thus, bands in lanes 3 and 4 do not align perfectly with those in the other lanes. 
Downloaded from genesdev.cshlp.org on April 26, 2023 - Published by Cold Spring Harbor Laboratory Press
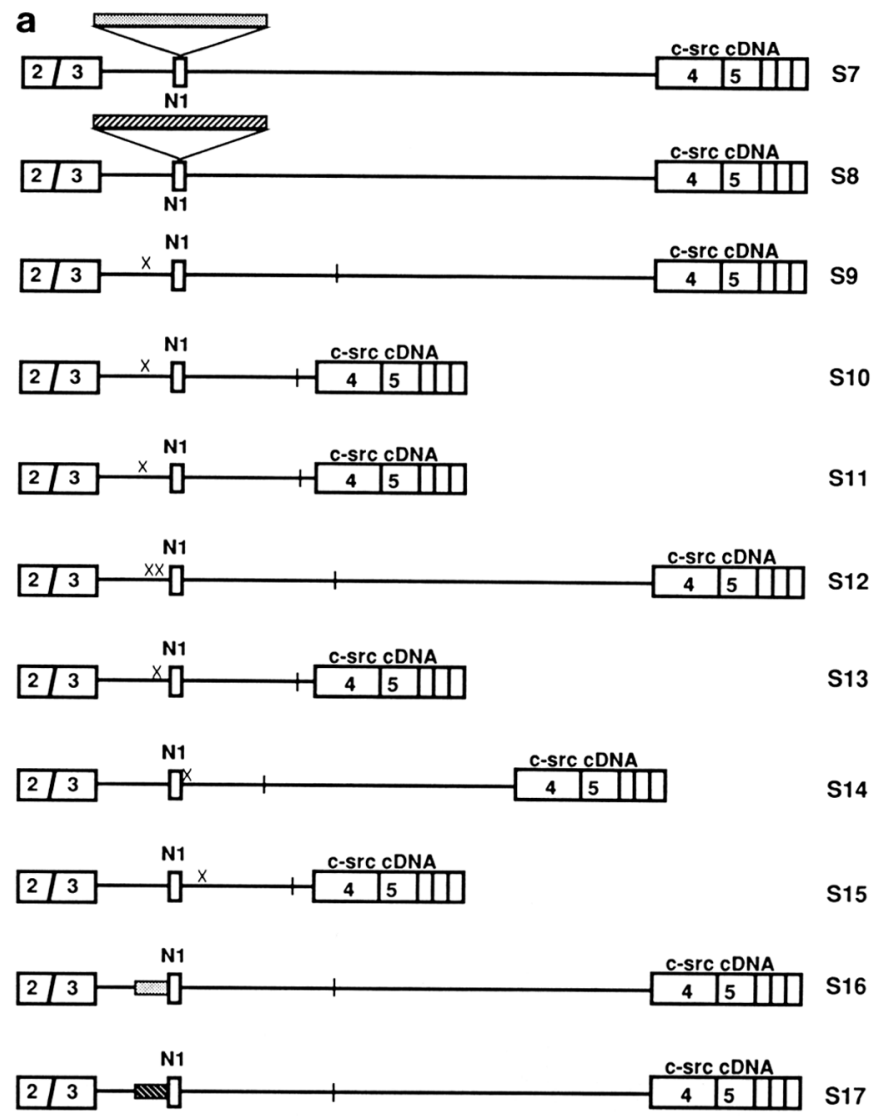

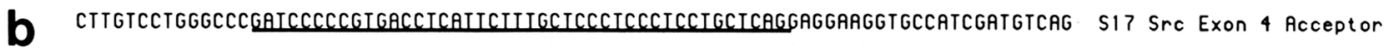

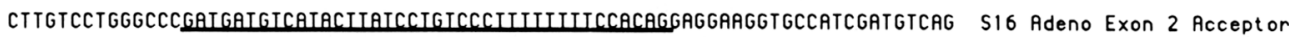

CTTGTCCTGGGCCCTGTCTTCGCACCTCAGCCTCTCCTTCTCTCTGCTICTCTCTCGCTGGCCCTTAGGAGGAAGGTGCCAICGATGTCAGGTGTGTACCGAGGCCAGGTAGAGGGGGATG S2

$$
\begin{aligned}
& \underset{S 9}{C C} \quad \frac{C C}{S 12} \quad C C C \quad T \quad \\
& \frac{T \quad T}{510} \frac{\pi T}{S 13} \\
& \frac{G C}{511}
\end{aligned}
$$

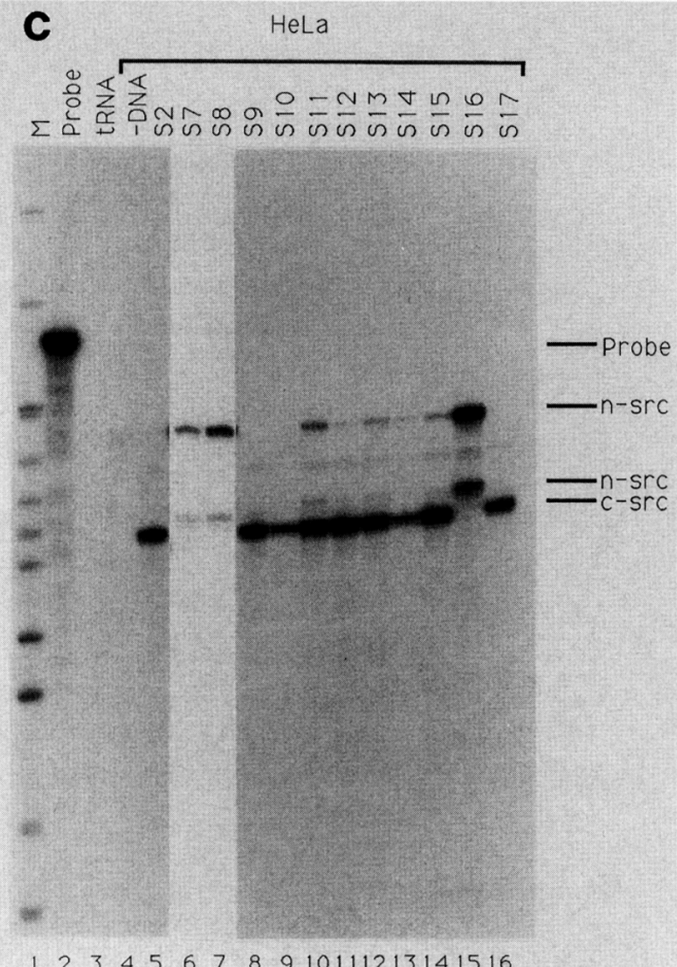

$\frac{A B \quad G}{S 14} \quad \frac{A \quad A C}{S 15}$

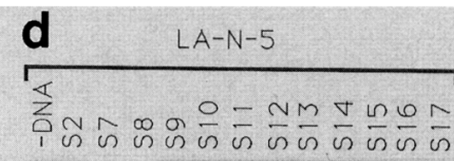

Figure 5. (See facing page for legend.) 
this regulation if placed in the context of the src N1 exon, two substitution mutations were made (see Fig. $5 \mathrm{a}, \mathrm{b})$. These replaced the N1 splice acceptor sequence from the ApaI site in intron 1 to the AG at the splice junction (54 nucleotides) with the 39 nucleotides upstream of the second leader exon of the adenovirus major late transcription unit (clone S16) or with 43 nucleotides of the acceptor sequence upstream of the constitutive $s r c$ exon 4 (clone S17). These two mutations gave strikingly different results. The adenovirus substitution gives constitutive insertion of the $\mathrm{Nl}$ exon in both HeLa and LA$\mathrm{N}-5$ cells (Fig. 5c, lane 15; Fig. 5d, lane 12). In contrast, the $\operatorname{src}$ exon 4 splice acceptor gave the opposite result. In this mutant, the N1 exon is not used in either cell type, producing only c-src mRNA in both HeLa (Fig. $5 c$, lane 16) and LA-N-5 (Fig. 5d, lane 13) cells. This splice junction sequence is completely functional in both $\mathrm{HeLa}$ and LA-N-5 cells in its normal context (attached to exon 4) but fails to be used in the $\mathrm{Nl}$ exon. (Note that the transferred sequence contains several putative branchpoint sequences, including a 4 of 5 match to the consensus 27 nucleotides upstream from the splice junction.) The 54 nucleotides upstream of the $\mathrm{N} 1$ exon thus have a large effect on the exon's utilization.

To test subtler changes in the splice sites, a series of point mutations were made on either side of the exon (see Fig. 5a,b). Several mutations were designed to alter sequence motifs common to both the chicken and mouse splice acceptors that might represent cis-acting regulatory elements. S9 and S10 contain different 2- and 3-nucleotide changes in the common sequence CTCAGC. In the mouse, the A within this sequence (position -40 ) is likely to be the branchpoint (see Discussion, below). Clone S12 has multiple substitutions in both copies of the sequence TTCTCTCT found in the polypyrimidine stretch of both the chicken and the mouse. These changes maintain the polypyrimidine character of the sequence (see Fig. 5b). Clone S13 has a smaller change ( 3 nucleotides) that also preserves the polypyrimidine stretch. Clone $\mathrm{S} 11$ also changes the putative branchpoint CTCAGC to CTGACC, making it match the consensus branchpoint sequence. Clone S14 improves the splice donor sequence, which is CAG/GTGTGTA in both chicken and mouse, to CAG/GTAAGTG, making it a perfect match to the consensus. The mutation in clone S15 changes 3 nucleotides in the sequence downstream of the Nl splice donor.

These mutations generally had smaller effects than the substitution of whole splice acceptor sequences (Fig. $5 c, d$ ), although several of the mutations did produce a significant increase in the amount of n-src mRNA in HeLa cells. This was most notable in the clones that improved the branchpoint and splice donor sequences. For S1 1 and S14 the amount of $\mathrm{n}$-src transcript in HeLa cells increased from $<1 \%$ to $9 \%$ or $10 \%$ (cf. lanes 10 and 13 with lane 5 in Fig. $5 c$; see Table 1). These mutations also increased the amount of $\mathrm{n}$-src splicing in LA-N-5 cells. This effect was strongest for S14, where $99 \%$ of the mRNA was now $\mathrm{n}$-src (Fig. 5d, lane 10). The mutations in the conserved polypyrimidine sequence ( $\mathrm{S} 12$ and $\mathrm{S} 13)$
Table 1. Quantification of $n$-src produced by various mutant src genes

\begin{tabular}{lccl}
\hline & \multicolumn{2}{c}{ Percent n-src } & \\
\cline { 2 - 3 } Clone & HeLa & LA-N-5 & Mutation \\
\hline S1 & $<1$ & 53 & \\
S2 & $<1$ & 65 & exon insertion \\
S3 & $<1$ & 39 & intron 1 deletion \\
S4 & $<1$ & 57 & intron 2 deletion \\
S5 & $<1$ & 43 & intron 2 deletion \\
S7 & 100 & 100 & exon insertion \\
S8 & 100 & 100 & exon insertion \\
S9 & $<1$ & 2 & substitutions in \\
& & & putative branchpoint \\
S10 & $<1$ & 21 & substitutions in \\
& & & putative branchpoint \\
S11 & 10 & 88 & improved putative \\
& & & branchpoint \\
S12 & 4 & 40 & pyrimidine substitutions \\
S13 & 7 & 87 & pyrimidine substitutions \\
S14 & 9 & 99 & improved 5' splice site \\
S15 & 6 & 66 & point mutation in intron 2 \\
S16 & 99 & 100 & adeno splice acceptor \\
S17 & $<1$ & 2 & src exon 4 splice acceptor \\
\hline
\end{tabular}

For a given clone the radioactivity in the c-src band and the upper and lower $\mathrm{n}$-src bands was counted. Because the probe is uniformly labeled, the radioactivity is proportional to the length of the protected fragment. Hence, the values for the c-src and the lower $n-s r c$ bands were normalized to the length of the upper $\mathrm{n}-s r c$ band. The percent $\mathrm{n}-s r c$ is defined as $\left(\mathrm{n}-s r c_{\text {upper }}+\right.$ $\left.\mathrm{n}-s r c_{\text {lower }}\right) /\left(\mathbf{n}-s r c_{\text {upper }}+\mathrm{n}-s r c_{\text {lower }}+\mathrm{c}-s r c\right) \times 100$. The values shown are for Figs. 3 and 5, using the mock transfected lanes as background. Other experiments gave similar results.

and clone $\mathrm{S} 15$ produced modest increases in the amount of $\mathrm{n}$-src mRNA in HeLa cells (Fig. 5c, lanes 11, 12, and 14). Clones S12 and S15 produced relatively normal ratios of $\mathrm{n}$-src to c-src in LA-N-5 $(40-70 \% \mathrm{n}$-src; cf. lanes 8 and 11 with lane 2 in Fig. $5 \mathrm{~d}$; see Table 1 ), whereas clone S13 showed an increase in the amount of n-src in LA-N-5 (lane 9). Two mutations decreased the use of the Nl exon in the LA-N-5 cells. S9 and S10 both decrease the match of the putative branchpoint to the consensus sequence. S9, which eliminates the expected branch A residue, drastically reduced the amount of $n$-src produced to $2 \%$. The amount of $n$-src produced by the various mutant clones in the two cell types is presented in Table 1.

Two splice acceptor mutations prevented the use of the N1 exon in either cell type (S9 and S17). It was possible that these changes inactivated the $\mathrm{Nl}$ splice acceptor such that it was completely dysfunctional. To test this idea, the mutant exons and flanking sequences were moved into the adenovirus clone in place of the adenovirus exon 2 and tested both as a whole exon, similar to clone $\mathrm{A} 4$, and as a half exon linked to the adenovirus exon 2 donor as in clone A5 (diagramed in Fig. 4a; assay in Fig. 6). The two whole exons containing mutant acceptor sequences were still inactive when placed between the two adenovirus exons, producing only the exon 1-3 spliced product in both HeLa and LA-N-5 cells (data not shown). However, juxtaposition of the adeno- 


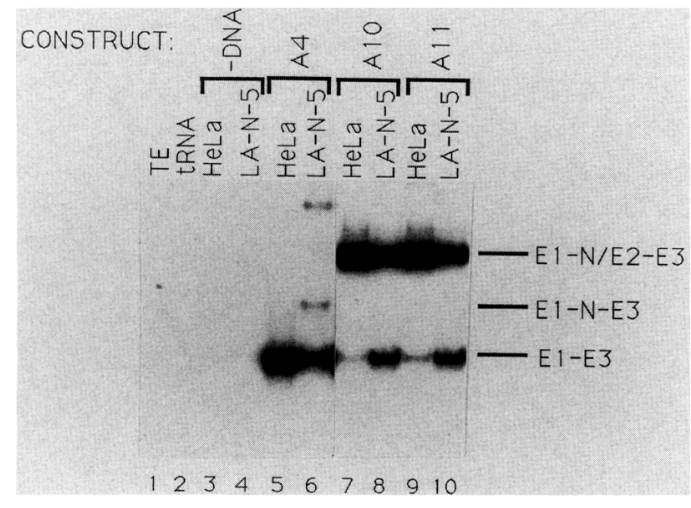

Figure 6. PCR assay of adenovirus/src hybrid genes containing mutant splice acceptors. The clones were transfected into $\mathrm{HeLa}$ and LA-N-5 cells and assayed by PCR as in Fig. 4b. (Lanes 1 and 2) As in Fig. 4b; (lanes 3, 5, 7, and 9) RNA from transfected HeLa cells; (lanes 4, 6, 8, and 10) RNA from transfected LA-N-5 cells. Cells were transfected with no DNA (lanes 3 and 4), clone A4 (lanes 5 and 6), A10 (lanes 7 and 8), and A11 (lanes 9 and 10). The spliced products are identified at right.

virus half-exon and splice donor sequence downstream from the $5^{\prime}$ half of the mutant $\mathrm{N} 1$ exons allowed the use of the previously inactive splice acceptors. In both HeLa and LA-N-5 cells there was a high level of inclusion of the hybrid exons (Fig. 6, lanes 7-10). In this case, there was more skipping of the hybrid exons in LA-N-5 cells $(\sim 30 \%$ skipped) than in HeLa $(10 \%)$. These results indicate that these splice acceptors can function in HeLa or LA-N-5 cells but are repressed in the context of the entire N1 exon. In another construct (data not shown) the N1 exon of clone S17 was lengthened with the same DNA fragment as in clone S8. Nearly all of the mRNA from this clone included the Nl exon in both HeLa and LA-N-5 cells (similar to S8). This result again implies that the exon 4 splice acceptor is potentially functional in the $\mathrm{N} 1$ context but is suppressed by the shortness of the exon.

\section{Discussion}

In this study I have analyzed the neural-specific splicing of the Nl exon from the mouse c-src gene. This exon is spliced into the endogenous src mRNA in LA-N-5 and At T-20 cells but is skipped in all non-neuronal cell lines tested, including 3T3 and HeLa (Fig. 2). When expressed from a transfected $s r c$ minigene, the $\mathrm{Nl}$ exon maintained its regulation; the exon was still included in mRNA from the transfected gene in AtT-20 and LA-N-5 cells and excluded in 3T3 and HeLa cells. This was true whether the transfected gene was expressed transiently or stably in a clonal cell line (Fig. 3; data not shown). By assaying the splicing pattern of mutant src genes, I sought to determine those elements that are required in cis to direct the neural-specific insertion of the $\mathrm{Nl}$ exon. Deleting intron sequences to within 55 nucleotides upstream of the N1 splice acceptor or to 141 nucleotides downstream of the splice donor had little effect on the control of the splicing of the exon (Fig. 3). The exons normally flanking N1 ( $s r c$ exons 3 and 4) were also unnecessary for its regulated use; when NI with portions of its flanking introns was cloned between two adenovirus exons, it was inserted into the mRNA only in LA-N-5 cells and not in HeLa (Fig. 4). Thus, the splice site "collaboration," seen in other systems between the donor and acceptor sequences of an intron, is not apparent for $\mathrm{Nl}$, as its neural specificity is maintained even when splicing to heterologous donor and acceptor sequences (Fu et al. 1988; Ulfendahl et al. 1989; Gallego and NadalGinard 1990). These experiments define the neural specificity of $\mathrm{N} 1$ as a property of the exon itself and the sequences immediately adjacent to it. On the other hand, the N1 splice junctions conform to the general consensus sequences and in the hybrid exons can function normally in non-neuronal cells (Fig. 4b). Thus, models for the regulation of the $\mathrm{N} 1$ exon must explain why these splice sites fail to be used in most cells, as well as how this repression is overcome in neurons.

\section{Repression by steric interference}

The N1 exon is quite small (18 nucleotides normally or 23 nucleotides with the Clal insertion). Since both halves seem to be required for its regulation (Fig. 4b), it was thought that repression of the exon in non-neural cells might require the interaction of factors bound at each end. Indeed, increasing the size of the $\mathrm{Nl}$ exon has a large effect on its regulation. Inserting several different fragments into the ClaI site of the exon /increasing its size from 23 to 108 or 109 nucleotides) allowed its efficient use in HeLa cells as well as LA-N-5 cells (Fig. 5, clones S7 and S8). Because the original 5-nucleotide insertion to form the ClaI site had no effect on the control of the exon, these insertions are unlikely to be interrupting a negative regulatory element within the exon. Moreover, all three inserted fragments allowed splicing in non-neural cells. Hence, the effect is probably not due to the activating function of a specific sequence in the insert. Thus, it appears that increasing the spacing between the two splice junction sequences allows the exon to be used in HeLa cells.

An internal exon like N1 must assemble a spliceosome complex at each end during the course of splicing. Nuclease protection studies of complexes bound over the splice sites during in vitro splicing reactions have delineated a protected region in the pre-mRNA upstream from the splice donor that is roughly the size of the $\mathrm{Nl}$ exon (17-18 nucleotides (Chabot and Steitz 1987a; Kramer 1987)]. Hence, the shortness of the N1 exon makes it likely that a spliceosome or prespliceosome complex bound at the acceptor site would interact and possibly interfere with a complex or factor bound at the donor site. Mutations that shorten the polyoma virus late leader exon from 57 to 9 nucleotides are thought to induce such an interfering effect (Adami and Carmichael 1987). Increasing the length of the N1 exon apparently overcomes this steric interference.

Because there are many known examples of small ex- 
ons, size alone cannot explain the repression of the $\mathrm{N} 1$ exon in HeLa cells. For instance, a 6-nucleotide exon has been reported in the cardiac troponin $\mathrm{T}$ gene /Cooper and Ordahl 1985). It may be that small exons need to have one rapidly used splice junction paired with a slowly used one. This would allow the formation of a splicing complex at one site to dominate over the other. Two sites where complexes assembled at the same rate would interfere with each other such that neither could form a productive spliceosome. This model implies that the sites in the $\mathrm{Nl}$ exon would be balanced in their rates of factor binding to achieve the repression in non-neural cells. In fact, point mutations that improve one of the two splice sites ( $\mathrm{S} 11$ and S14) do have the effect of activating the use of the exon in HeLa cells (Fig. 5). The mutations in clones S12, S13, and S15 that also increase exon inclusion in HeLa cells may also be affecting the rates of factor binding to the polypyrimidine sequence or the splice donor site. An attractive aspect of this model is that for any short exon, the balance between the two splice sites will determine its level of inclusion into the mRNA without the need for special factors or structures in the pre-mRNA.

It is possible that rather than just moving the two splice sites apart, the insertion mutations are splitting some other inhibitory interaction spanning the exon. Two previously proposed models for interactions across exons invoke either RNA secondary structure (Solnick 1985a) or the binding of factors at the splice junctions (Robberson et al. 1990). Sequestering exons or splice sites of synthetic splicing substrates within RNA secondary structures can induce exon skipping (Solnick 1985a; Eperon et al. 1988). Putative stable secondary structures can be predicted for the murine $\mathrm{Nl}$ exon using computer RNA folding programs (Jaeger et al. 1989). Unfortunately, so far, I have not found a structure that is conserved in the chicken sequence. Furthermore, one might expect mutations that make extensive base changes, such as S12, S16, and S17, to destabilize the structure leading to exon inclusion in HeLa cells. This is not seen in $\mathrm{S} 17$ and only partially in S12. In vitro studies of an adenovirus transcript indicated that the presence of a downstream splice donor could enhance the splicing complex formation at a splice acceptor (Robberson et al. 1990). It was proposed that factors bound at one splice site could reach across the exon to promote the binding of factors at the other splice site. In contrast, the interaction across the $\mathrm{N} 1$ exon seems to be a negative one that results from the close spacing of the two sites. That this negative interaction is mediated by constitutive splicing factors (the model that I favor) rather than other unidentified factors has not yet been proved.

\section{Neuronal activation of the exon}

The simplest models for the regulation of the $\mathrm{Nl}$ exon invoke a single tissue-specific factor (like the Sex lethal protein) that either represses the use of the exon in nonneuronal cells or activates it in neurons. If repression of the src exon in non-neuronal cells is due to the steric interference of splicing complexes assembling at each end, then activation of the exon in neurons could result from anything that changed the relative rates of complex formation at the two sites. This could result from a tissue-specific factor that affected assembly at one of the sites. However, even subtle changes in the general splicing factor concentrations between neurons and other cells might have such an effect, and so the need for a single RNA element and a tissue-specific factor that binds to it is open to question. Indeed, such a singletissue specific element has been difficult to find in the Drosophila P-element system (Laski and Rubin 1989).

Several point mutations in the splice sites increased the use of the N1 exon in HeLa cells (Fig. 5). However, the increase in splicing is never very high (up to $10 \%$ ), and these mutations usually also increase the inclusion of N1 in LA-N-5 cells (Table 1). For example, the S4 clone, which shows normal regulation, inserts the $\mathrm{N} 1$ exon into $<1 \%$ of its mRNA in HeLa cells and $\sim 57 \%$ in LA-N-5 cells. Changing the putative branchpoint of this clone to match the consensus sequence (clone S11) increases the use of the exon in HeLa cells to $10 \%$ of the mRNA, but the LA-N-5 cells now insert the exon in $88 \%$ of their mRNA. Thus, the activation of the exon in LA$\mathrm{N}-5$ cells seems to occur on top of the higher basal level of splicing seen in HeLa cells. This higher basal level of exon inclusion is presumably determined by a change in the relative rates of factor binding to the two splice sites.

Exchanging the sequence upstream of the acceptor AG in the N1 exon with the sequence of a constitutive splice acceptor had more drastic effects on the splicing of the exon (Fig. 5). Substitution of the 3' splice site from the second adenovirus leader exon (clone S16) produced complete use of $\mathrm{Nl}$ in both cell types. The splicing to this site is not suppressed in HeLa by the rest of the N1 exon and donor site. This splice acceptor is known to be a particularly strong site in in vitro splicing reactions (D. Black, unpubl.). Thus, spliceosome assembly at this site may occur fast enough to effectively compete for factor binding at the $\mathrm{Nl}$ splice donor. In fact, this effect is not seen with all constitutive splice sites. When the splice junction sequence upstream from $s r c$ exon 4 is placed upstream from exon $\mathrm{N} 1(S 17)$, the exon is skipped in both HeLa and LA-N-5 cells. Surprisingly, moving this normally constitutive acceptor sequence into the context of the $\mathrm{Nl}$ exon can silence the site even in a cell type where $\mathrm{Nl}$ is usually active.

Another mutation $|\mathrm{S} 9|$ in the N1 splice acceptor had the same effect as the exon 4 acceptor substitution (S17). Changing the dinucleotide at position -39 to the splice junction from AG to CC prevented use of the exon in either cell type. This A residue is likely to be the branchpoint (Reed 1989; Smith et al. 1989b). It is the first A upstream from the splice junction after the polypyrimidine tract. It is within a 3 of 5 match to the branchpoint consensus sequence, and the fact that it is an AG sequence makes it unlikely that the branch site will be much farther upstream. Thus, the N1 exon does not seem to have a distal branchpoint as found in other systems (Chebli et al. 1989; Smith and Nadal-Ginard 1989), 
although mapping of the branchpoint after in vitro splicing will be needed to prove this. It is somewhat surprising that a branchpoint mutation would inactivate the splice site; in other genes mutation of the branchpoint leads to activation of cryptic branchpoints upstream without the loss of function (Padgett et al. 1985; Ruskin et al. 1985). (Note that there is another 3 of 5 match to the branchpoint consensus immediately upstream of this mutation.)

Both of these inactive splice acceptors ( $\mathrm{S} 9$ and $\mathrm{S17}$ ) are functional in HeLa or LA-N-5 cells in the hybrid src/ adenovirus exons (Fig. 6). The S17 splice acceptor is also active in both cell types if the exon is lengthened as in clone S8 (data not shown). Yet the short N1 exon in the S9 and S17 clones apparently cannot function properly in LA-N-5 cells. Thus, these sites may be blocked by the $5^{\prime}$ splice site downstream (similar to the normal acceptor) but are lacking a feature that allows the normal site to be activated in LA-N-5 cells. This implies that the mechanism allowing inclusion of the exon in neurons acts at least in part through the splice acceptor sequence.

The deletion analysis defined the sequences required for $\mathrm{N} 1$ exon regulation to a region of $\sim 210$ nucleotides. However, a single sequence within this region responsible for the neural specificity of the exon has not yet been found. Although the splice acceptor may contain such an element, neither of two sequences conserved between the chicken and mouse acceptors is the sole determinant of the tissue specificity. The LA-N-5 activation is still seen in mutations that change these sequences $[\mathrm{S} 11$ and S12). In several studies of other genes, mutations in tissue-specific exons altered their pattern of use (Mardon et al. 1987; Cooper and Ordahl 1989; Hampson et al. 1989; Laski and Rubin 1989; Streuli and Saito 1989; Nagoshi and Baker 1990). This has not been found here. Two changes in the $\mathrm{N} 1$ exon sequence itself had no effect on its utilization. The ClaI site insertion, which adds 5 nucleotides into the exon (see Fig. 3), is in nearly all the constructs tested and behaves normally. Another mutation, which changes the exon sequence AAGGTGG to AATTCGG for a 3-base substitution, also had little detectable effect on the regulation of the exon /data not shown). There are also several nucleotide changes between the mouse and the chicken exons. More mutations will be required to rigorously determine the contribution of the remaining exon and intron sequences to the tissue specificity.

The interference of splicing complexes binding at closely spaced sites has been demonstrated or postulated in several other systems. The mutually exclusive exons in the $\alpha$-tropomyosin gene are prevented from splicing to each other by the short distance from the donor site of one exon to a distal branchpoint of the exon downstream (Smith and Nadal-Ginard 1989). In another study the insertion of a new synthetic splice donor site close to the normal splice donor of a $\beta$-globin intron could prevent splicing to the normal as well as the inserted site in vitro (Nelson and Green 1988). This type of interference by multiple splice donors has been postulated to play a role in the inhibition of Drosophila P-element splicing (Sie- bel and Rio 1990). These results and those with the src exon may point to a mechanism for the general repression of certain splicing events through use of multiple potentially functional splice sites whose spacing is in some way incompatible. How splicing to a single site might be activated in specific tissues remains mysterious.

\section{Materials and methods}

\section{Sequencing}

Genomic clones of the src locus from the mouse and the chicken were obtained from Drs. Ricardo Martinez and Lu-Hai Wang, respectively. The smaller intron was also cloned from chicken genomic DNA by PCR amplification using the primers: CTGTCCTTCAAGAAAGGGGAGC (homologous to exon 3) and ACCTGACGTCCACTTTTCTCCT (complementary to exon N1) (Levy et al. 1987). The relevant portions of these clones were subcloned into the vector pBSK (Stratagene) and sequenced by the chain termination method. This was performed on either single- or double-stranded DNA using the Sequenase enzyme (U.S. Biochemicals) according to the manufacturer's protocol.

\section{DNA constructions}

All clones were constructed using standard methods (Ausubel et al. 1987; Maniatis et al. 1989), and most were confirmed by sequencing. The $\mathrm{S}$ series of clones was derived from the $\mathrm{n}$-SIC expression plasmid pVN1.8 (Martinez et al. 1987). This clone contains the mouse n-sIC cDNA between the two Moloney murine leukemia virus LTRs to provide promoter/enhancer and polyadenylation functions. Clone S1 contains a fragment of mouse src genomic DNA from the BstEIl site in exon 3 to the NarI site in exon 4. The BstEII site was fused to the first SacII site in $s r c$ exon 2 of pVNl.8 after blunting the fragment ends. The NarI site of exon 4 in the genomic fragment was joined directly to the NarI site in exon 4 of pVN1.8. This site was then recut with Narl, the ends were filled in with DNA polymerase (Klenow enzyme), and a 10-nucleotide NotI linker was inserted. The $\sim 2.5$-kb fragment between the two BamHI sites in the second intron of the construct was also deleted.

In the S2 clone, a ClaI site was inserted in the N1 exon of S1. The sequence of the exon was changed to that shown in Figure 3 by the gapped heteroduplex method (Lenardo et al. 1987).

The S3 clone was produced by cleaving S2 with NaeI and Apal, trimming the ApaI ends with T4 DNA polymerase, and religating the large fragment produced by the cleavage. This deletes 96 nucleotides from the middle of the first intron.

S4 is another deletion of S2. In this clone, the sequence between the first SmaI site in intron 2 and the BstEII site 55 nucleotides upstream of exon 4 was replaced with a BamHI linker.

The S5 clone deletes the sequence from 141 nucleotides downstream of exon $\mathrm{N} 1$ to the BamHI site in S2. This was done by using PCR to amplify the sequence downstream of exon N1 in clone S2 using the primers GGAAGGTGCCATCGATGTCAG (homologous to exon N1) and GAAGATGGATCCCGGGTACGGCTCAT (complementary to intron 2). This amplification product was cut with $C l a I$ and $B a m H I$ and inserted into S2 DNA, which had also been cut with ClaI and BamHI. The S14 clone was made in the same way as S5, except that the $\mathrm{Nl}$ exon primer contained the mutation shown in Figure 5 .

The S7 and S8 clones had fragments inserted into the ClaI site 
of S2. In S7 the inserted fragment was an 85-bp TaqI-MaeII fragment from the third exon of src. In S8 the fragment was an 86-bp AccI-Ahall fragment from the second intron of the adenovirus major late transcription unit.

In clones $S 9, S 12, S 16$, and S17, the sequences shown in Figure $5 \mathrm{~b}$ between the ApaI site and the ClaI site were synthesized as long oligonucleotides and inserted in place of the normal $A p a-$ Cla fragment of S2.

The $s r c$ sequence of S4 was recloned into the pBSK vector (Stratagene), which can be rescued as a single-stranded phagemid. This was used to generate the site-specific mutations in clones S10, S11, S13, and S15, employing the Kunkel procedure (Kunkel 1985). These genes were then moved back into clone S4 for expression in cells.

The Al clone was derived from a clone of the adenovirus major late transcription unit pSPAd (Solnick 1985b), which was modified by the insertion of a SmaI linker into the ScaI site of adenovirus exon 2. pSPAd also contains deletions that shorten the first two introns of the transcription unit to 243 and 776 nucleotides, respectively (Solnick 1985b). To make clone A1, the sequence from the PvuII site in adenovirus exon 1 to the Xhol site in exon 3 was inserted into the SmaI site of the CMVbased expression vector pEVRF1 (Matthias et al. 1989).

Clone A4 was constructed by using the NaeI-SmaI fragment of src DNA that contains the $\mathrm{N} 1$ exon (Fig. 1b). Clone A4 replaces a SacIl fragment containing the adenovirus exon 2 with this src fragment. These SacIl sites are 152 nucleotides upstream and 623 nucleotides downstream from the ends of the adenovirus exon 2. Clone A7 simply deletes this fragment.

Clone A5 replaces the adenovirus sequence from the HindIII site in intron 1 to the $S m a I$ site in exon 2 with src sequence from the NaeI site in src intron 1 to the ClaI site in the Nl exon. Clone A6 replaces the adenovirus sequence from the SmaI site in exon 2 to the Sall site in intron 2 with the src sequence from the ClaI site in exon $\mathrm{Nl}$ to the first SmaI site in intron 2. Clones $\mathrm{AlO}$ and $\mathrm{All}$ are equivalent to clone A.5 except that the src DNA in Al0 and All is from clones S17 and S9, respectively.

\section{Cell culture}

All cells were grown as adherent monolayers on $10-\mathrm{cm}$ tissue culture petri dishes. HeLa cells were grown in Dulbecco's modified Eagle (DME) medium plus $10 \%$ calf serum. LA-N-5 cells (obtained from Dr. Robert Weinberg) were grown in a medium containing $42.5 \%$ DME, $42.5 \%$ F 12 medium, and $15 \%$ fetal calf serum.

\section{DNA transfection}

The cells were transfected by the calcium phosphate precipitation method (Graham and Van der Eb 1973; Parker and Stark 1979 ). One $10-\mathrm{cm}$ plate $(25 \%$ confluent for HeLa or $80 \%$ confluent for LA-N-5) was transfected with $10 \mu \mathrm{g}$ of plasmid DNA. After $48 \mathrm{hr}$, RNA was isolated from the cells by the NP-40 lysis method (Ausubel et al. 1987).

\section{RNase protection}

RNase protection reactions were generally performed on $30 \mu \mathrm{g}$ of total cytoplasmic RNA following the standard protocol (Melton et al. 1984/ except that the hybridization was done at $65^{\circ} \mathrm{C}$ for $3 \mathrm{hr}$ and the RNase digestion was at $37^{\circ} \mathrm{C}$ for $1 \mathrm{hr}$. One-half of each RNase-treated sample was run on an $8 \%$ polyacrylamide gel containing TBE buffer and $7.5 \mathrm{M}$ urea (Maniatis et al. 1989). These gels were then autoradiographed. The ratios of the spliced products were measured by counting the radioactivity in each band on a Betascope 603 (Betagen). The probe was an antisense SP6 transcript of the mouse n-src cDNA from the Avall site in exon 5 to the PstI site in exon 3 cloned into pGEM-4 (PromegaBiotec).

\section{PCR assays}

The PCR assays for splicing of the Nl exon were performed as follows. Three oligonucleotide primers were used for the assay. For measuring the endogenous $s r c$ transcripts the primers were: (1) ACCACTCCTCAGCCTGGATGG, complementary to src exon 4 ; (2) TGGATGGAGTCGGAGGGCGC, complementary to $\operatorname{src}$ exon 4; (3) CTGTCCTTCAAGAAAGGGGAGC, homologous to $s r c$ exon 3 . For measuring the splicing of the adenovirus clones, the oligonucleotides were (1) CTCAAGGGGCTTCATGATGTCC, complementary to the $\beta$-globin trailer sequences in pEVRFl; (2) TCCGATCCGGTCGATGCGGACTCG, complementary to the third exon of the adenovirus major late transcription unit; (3) CAGCGCCTTGTAGAAGCGCGTATG, homologous to the leader sequence of pEVRF1. To make cDNA of the mRNA, $3 \mu \mathrm{g}$ of total cytoplasmic RNA was hybridized to $3 \mathrm{ng}$ of primer 1 and reverse-transcribed according to the protocol of Smale and Baltimore (1989), except that the total volume was $25 \mu \mathrm{l}$. After reverse transcription, the sample was diluted to $500 \mu \mathrm{l}$ with TE, boiled for $2 \mathrm{~min}$, and placed on ice.

Two microliters of this cDNA sample was used in a $50-\mu \mathrm{l}$ PCR reaction that contained $10 \mathrm{mM}$ Tris $-\mathrm{HCl} \mid \mathrm{pH} 8.4$ at room temperature), $50 \mathrm{mM} \mathrm{KCl}, 1.5 \mathrm{mM} \mathrm{MgCl}_{2}, 20 \mu \mathrm{g} / \mathrm{ml}$ of gelatin, $200 \mu \mathrm{M}$ each dNTP, $0.14 \mu \mathrm{M}$ primer $2,0.14 \mu \mathrm{M}$ primer 3,1 unit of Taq DNA polymerase, and $1 \mu \mathrm{Ci}\left[\alpha-{ }^{32} \mathrm{P}\right] \mathrm{dCTP}[800 \mathrm{Ci} /$ mmole).

The PCR reactions included 30 cycles of $94^{\circ} \mathrm{C}$ for $1 \mathrm{~min}$, annealing temperature for $1 \mathrm{~min}$, and $72^{\circ} \mathrm{C}$ for $1 \mathrm{~min}, 45 \mathrm{sec}$. This was followed by $72^{\circ} \mathrm{C}$ for $10 \mathrm{~min}, 94^{\circ} \mathrm{C}$ for $1 \mathrm{~min}$, and a 1 -hr slow cooling to room temperature. The annealing temperatures for the $s r c$ and adenovirus primers were $48^{\circ} \mathrm{C}$ and $55^{\circ} \mathrm{C}$, respectively. One-tenth of each reaction was then separated on a nondenaturing gel and autoradiographed. The reactions can also be run without the radiolabel and stained with ethidium and blotted. The gel in Figure 2 is $4 \%$ nusieve agarose $0.5 \times$ TBE. The gels in Figures 4 and 6 are $8 \%$ acrylamide, $1 \times$ TBE.

\section{Acknowledgments}

I am indebted to Ricardo Martinez for initiating this project and providing several clones, particularly the unpublished genomic mouse src clone. I also thank Lu-Hai Wang, Joseph Bolen, and Joanna Pyper for clones and unpublished information; Phil Sharp, Don Rio, and Chris Siebel for helpful discussions; and David Baltimore, Joan Steitz, Don Rio, Chris Siebel, and Barbara Ruskin for useful comments on the manuscript. Finally, I am particularly grateful to David Baltimore, in whose laboratory this work was performed, for his support and encouragement throughout the course of this project. This work was supported by a fellowship from the Helen Hay Whitney Foundation and by grant (1RO1 CA 51462-01) from the National Cancer Institute to David Baltimore.

The publication costs of this article were defrayed in part by payment of page charges. This article must therefore be hereby marked "advertisement" in accordance with 18 USC section 1734 solely to indicate this fact.

\section{References}

Adami, G.R. and G.G. Carmichael. 1987. The length but not the sequence of the polyoma virus late leader exon is important 
for both late RNA splicing and stability. Nucleic Acids Res. 15: 2593-2610.

Ausubel, F.M., R. Brent, R.E. Kingston, D.D. Moore, J.G. Seidman, J.A. Smith, and K. Struhl. 1987. Current protocols in molecular biology. John Wiley/Greene, New York.

Baker, B.S. 1989. Sex in flies: The splice of life. Nature 340: 521-524.

Bishop, J.M. and H. Varmus. 1985. Functions and origins of retroviral transforming genes. In RNA tumor viruses. The molecular biology of tumor viruses (ed. R. Weiss, N. Teich, H. Varmus, and J. Coffin), vol. 2/suppl. Cold Spring Harbor Laboratory, Cold Spring Harbor, New York.

Chabot, B. and J.A. Steitz. 1987a. Multiple interactions between the splicing substrate and small nuclear ribonucleoproteins in spliceosomes. Mol. Cell. Biol. 7: 281-293.

. 1987b. Recognition of mutant and cryptic 5' splice sites by the Ul small nuclear ribonucleoprotein in vitro. Mol. Cell. Biol. 7: 698-707.

Chebli, K., R. Gattoni, P. Schmitt, G. Hildwein, and J. Stevenin. 1989. The 216-nucleotide intron of the E1A pre-mRNA contains a hairpin structure that permits utilization of unusually distant branch acceptors. Mol. Cell. Biol. 9: 4852-4861.

Cooper, T.A. and C.P. Ordahl. 1985. A single cardiac troponin T gene generates embryonic and adult isoforms via developmentally regulated alternate splicing. I. Biol. Chem. 260: 11140-11148.

- 1989. Nucleotide substitutions within the cardiac troponin $\mathrm{T}$ alternative exon disrupt pre-mRNA alternative splicing. Nucleic Acids Res. 17: 7905-7921.

Drubin, D.G., J. Mulholland, Z.M. Zhu, and D. Botstein. 1990. Homology of a yeast actin-binding protein to signal transduction proteins and myosin-I. Nature 343: 288-290.

Emeson, R.B., F. Hediran, J.M. Yeakley, J.W. Guise, and M.G. Rosenfeld. 1989. Alternative production of calcitonin and CGRP mRNA is regulated at the calcitonin-specific splice acceptor. Nature 341: 76-80.

Eperon, L.P., I.R. Graham, A.D. Griffiths, and I.C. Eperon. 1988. Effects of RNA secondary structure on alternative splicing of pre-mRNA: Is folding limited to a region behind the transcribing RNA polymerase? Cell 54: 393-401.

Fu, X.Y., H. Ge, and J.L. Manley. 1988. The role of the polypyrimidine stretch at the SV40 early pre-mRNA $3^{\prime}$ splice site in alternative splicing. EMBO I. 7: 809-817.

Gallego, M.E. and B. Nadal-Ginard. 1990. Myosin light-chain 1/3 gene alternative splicing: cis regulation is based upon a hierarchical compatibility between splice sites. Mol. Cell. Biol. 10: 2133-2144.

Garcia-Blanco, M., S.F. Jamison, and P.A. Sharp. 1989. Identification and purification of a 62,000 -dalton protein that binds specifically to the polypyrimidine tract of introns. Genes $\&$ Dev. 3: 1874-1886.

Ge, H. and J.L. Manley. 1990. A protein factor, ASF, controls cell-specific alternative splicing of SV40 early pre-mRNA in vitro. Cell 62: 25-34

Gerke, V. and J.A. Steitz. 1986. A protein associated with small nuclear ribonucleoprotein particles recognizes the $3^{\prime}$ splice site of premessenger RNA. Cell 47: 973-984.

Graham, G.L. and A.J. Van der Eb. 1973. A new technique for the assay of infectivity of human adenovirus 5 DNA. 52: 456-467.

Guthrie, C. and B. Patterson. 1988. Spliceosomal snRNAs. Annu. Rev. Genet. 22: 387-419.

Hampson, R.K., F.L. La, and F.M. Rottman. 1989. Alternative processing of bovine growth hormone mRNA is influenced by downstream exon sequences. Mol. Cell. Biol. 9: 16041610 .
Helfman, D.M., W.M. Ricci, and L.A. Finn. 1988. Alternative splicing of tropomyosin pre-mRNAs in vitro and in vivo. Genes \& Dev. 2: 1627-1638.

Helfman, D.M., R.F. Roscigno, G.J. Mulligan, L.A. Finn, and K.S. Weber. 1990. Identification of two distinct intron elements involved in alternative splicing of beta-tropomyosin pre-mRNA. Genes \& Dev. 4: 98-110.

Inoue, K., K. Hoshijima, H. Sakamoto, and Y. Shimura. 1990. Binding of the Drosophila sex-lethal gene product to the alternative splice site of transformer primary transcript. $\mathrm{Na}$ ture 344: 461-463.

Jaeger, J.A., D.H. Turner, and M. Zucker. 1989. Improved predictions of secondary structure for RNA. Proc. NatI. Acad. Sci. 86: $7706-7710$.

Konarska, M.M. and P.A. Sharp. 1987. Interactions between small nuclear ribonucleoprotein particles in formation of spliceosomes. Cell 49: 763-774.

Krainer, A.R. and T. Maniatis. 1988. RNA splicing. In Frontiers in molecular biology: Transcription and splicing (ed. B.D. Hames and D.M. Glover), pp. 131-206. IRL Press, Oxford/ Washington, D.C.

Krainer, A.R., G.C. Conway, and D. Kozak. 1990. The essential pre-mRNA splicing factor SF2 influences 5' splice site selection by activating proximal sites. Cell 62: 35-42.

Kramer, A. 1987. Analysis of RNase-A-resistant regions of adenovirus 2 major late precursor-mRNA in splicing extracts reveals an ordered interaction of nuclear components with the substrate RNA. J. Mol. Biol. 196: 559-573.

Kunkel, T.A. 1985. Rapid and efficient site-specific mutagenesis without phenotypic selection. Proc. Natl. Acad. Sci. 82: 488-492.

Lamond, A.I., M.M. Konarska, and P.A. Sharp. 1987. A mutational analysis of spliceosome assembly: Evidence for splice site collaboration during spliceosome formation. Genes \& Dev. 1: 532-543.

Laski, F.A. and G.M. Rubin. 1989. Analysis of the cis-acting requirements for germ-line-specific splicing of the $\mathrm{P}$ element ORF2-ORF3 intron. Genes \& Dev. 3: 720-728.

Lenardo, M., J.W. Pierce, and D. Baltimore. 1987. Protein-binding sites in $\mathrm{Ig}$ gene enhancers determine transcriptional activity and inducibility. Science 236: 1573-1577.

Levy, J.B., T. Dorai, L.H. Wang, and J.S. Brugge. 1987. The structurally distinct form of pp60c-src detected in neuronal cells is encoded by a unique c-src mRNA. Mol. Cell. Biol. 7: 4142-4145.

Maniatis, T., E.F. Fritsch, and J. Sambrook. 1989. Molecular cloning: A laboratory manual, 2nd ed. Cold Spring Harbor Laboratory Press, Cold Spring Harbor, New York.

Mardon, H.J., G. Sebastio, and F.E. Baralle. 1987. A role for exon sequences in alternative splicing of the human fibronectin gene. Nucleic Acids Res. 15: 7725-7733.

Martinez, R., B. Mathey-Prevot, A. Bernards, and D. Baltimore. 1987. Neuronal pp60c-src contains a six-amino acid insertion relative to its non-neuronal counterpart. Science 237: 411-415.

Matthias, P., M.M. Muller, E. Schreiber, S. Rusconi, and W. Schaffner. 1989. Eukaryotic expression vectors for the analysis of mutant proteins. Nucleic Acids Res. 17: 6418.

Melton, D.A., P.A. Krieg, M.R. Rebagliati, T. Maniatis, K. Zinn, and M.R. Green. 1984. Efficient in vitro synthesis of biologically active RNA and RNA hybridization probes from plasmids containing a bacteriophage SP6 promoter. Nucleic Acids Res. 12: 7035-7056.

Nagoshi, R.N. and B.S. Baker. 1990. Regulation of sex-specific RNA splicing at the Drosophila doublesex gene: Cis-acting mutations in exon sequences alter sex-specific RNA splicing 
patterns. Genes \& Dev. 4: 89-97.

Nasim, F.H., P.A. Spears, H.M. Hoffmann, H. Kuo, and P.J. Grabowski. 1990. A sequential splicing mechanism promotes selection of an optional exon by repositioning a downstream 5' splice site in preprotachykinin pre-mRNA. Genes \& Dev. 4: 1172-1184.

Nelson, K.K. and M.R. Green. 1988. Splice site selection and ribonucleoprotein complex assembly during in vitro premRNA splicing. Genes \& Dev. 2: 319-329.

Padgett, R.A., M.M. Konarska, M. Aebi, H. Hornig, C. Weissmann, and P.A. Sharp. 1985. Nonconsensus branch-site sequences in the in vitro splicing of transcripts of mutant rabbit beta-globin genes. Proc. Natl. Acad. Sci. 82: 8349-8353.

Parker, B.A. and G.R. Stark. 1979. Regulation of simian virus 40 transcription: Sensitive analysis of the RNA species present early in infections by virus or viral DNA. I. Virol. 31:360369.

Parker, R., P.G. Siliciano, and C. Guthrie. 1987. Recognition of the TACTAAC box during mRNA splicing in yeast involves base pairing to the U2-like snRNA. Cell 49: 229-239.

Pawson, T. 1988. Non-catalytic domains of cytoplasmic protein-tyrosine kinases: Regulatory elements in signal transduction. Oncogene 3: 491-495.

Pyper, J.M. and J.B. Bolen. 1990. Identification of a novel neuronal C-SRC exon expressed in human brain. Mol. Cell. Biol. 10: $2035-2340$.

Reed, R. 1989. The organization of $3^{\prime}$ splice-site sequences in mammalian introns. Genes \& Dev. 3: 2113-2123.

Reed, R. and T. Maniatis. 1986. A role for exon sequences and splice-site proximity in splice-site selection. Cell 46: 681690.

Robberson, B.L., G.J. Cote, and S.M. Berget. 1990. Exon definition may facilitate splice site selection in RNAs with multiple exons. Mol. Cell. Biol. 10: 84-94.

Ruby, S.W. and J. Abelson. 1988. An early hierarchic role of Ul small nuclear ribonucleoprotein in spliceosome assembly. Science 242: 1028-1035.

Ruskin, B., J.M. Greene, and M.R. Green. 1985. Cryptic branch point activation allows accurate in vitro splicing of human beta-globin intron mutants. Cell 41: 833-844.

Ruskin, B., P.D. Zamore, and M.R. Green. 1988. A factor, U2AF, is required for U2 snRNP binding and splicing complex assembly. Cell 52: 207-219.

Seraphin, B. and M. Rosbash. 1989. Identification of functional Ul snRNA-pre-mRNA complexes committed to spliceosome assembly and splicing. Cell 59: 349-358.

Seraphin, B., L. Kretzner, and M. Rosbash. 1988. A Ul snRNA: Pre-mRNA base pairing interaction is required early in yeast spliceosome assembly but does not uniquely define the $5^{\prime}$ cleavage site. EMBO I. 7: 2533-2538.

Shapiro, M.B. and P. Senapathy. 1987. RNA splice junctions of different classes of eukaryotes: Sequence statistics and functional implications in gene expression. Nucleic Acids Res. 15: 7155-7174.

Siebel, C.W. and D.C. Rio. 1990. Regulated splicing of the Drosophila $P$ transposable element third intron in vitro: Somatic repression. Science 248: 1200-1208.

Siliciano, P.G. and C. Guthrie. 1988. 5' splice site selection in yeast: Genetic alterations in base-pairing with $\mathrm{U} 1$ reveal additional requirements. Genes \& Dev. 2: 1258-1267.

Smith, C.W. and B. Nadal-Ginard. 1989. Mutually exclusive splicing of alpha-tropomyosin exons enforced by an unusual lariat branch point location: Implications for constitutive splicing. Cell 56: 749-758.

Smith, C.W., J.G. Patton, and B. Nadal-Ginard. 1989a. Alternative splicing in the control of gene expression. Annu. Rev.
Genet. 23: 527-577.

Smith, C.W., E.B. Porro, J.G. Patton, and B. Nadal-Ginard. $1989 \mathrm{~b}$. Scanning from an independently specified branch point defines the $3^{\prime}$ splice site of mammalian introns. $\mathrm{Na}$. ture 342: 243-247.

Solnick, D. 1985a. Alternative splicing caused by RNA secondary structure. Cell

- 1985b. Trans splicing of mRNA precursors. Cell 42: $157-164$.

Somasekhar, M.B. and J.E. Mertz. 1985. Exon mutations that affect the choice of splice sites used in processing the SV40 late transcripts. Nucleic Acids Res. 13: 5591-5609.

Sosnowski, B.A., J.M. Belote, and M. McKeown. 1989. Sex-specific alternative splicing of RNA from the transformer gene results from sequence-dependent splice site blockage. Cell 58: $449-459$.

Steitz, J.A., D.L. Black, V. Gerke, K.A. Parker, A. Kramer, D. Frendewey, and W. Keller. 1988. Functions of the abundant U snRNPs. In Structure and function of major and minor small nuclear ribonucleoprotein particles (ed. M.L. Birnstiel). Springer-Verlag, Berlin and Heidelberg.

Streuli, M. and H. Saito. 1989. Regulation of tissue-specific alternative splicing: Exon-specific cis-elements govern the splicing of leukocyte common antigen pre-mRNA. EMBO $J$. 8: 787-796

Swanson, M.S. and G. Dreyfuss. 1988. RNA binding specificity of hnRNP proteins: A subset bind to the $3^{\prime}$ end of introns. EMBO J. 7: 3519-3529.

Tazi, J., C.. Alibert, J. Temsamani, I. Reveillaud, G. Cathala, C. Brunel, and P. Jeanteur. 1986. A protein that specifically recognizes the $3^{\prime}$ splice site of mammalian pre-mRNA introns is associated with a small nuclear ribonucleoprotein. Cell 47: $755-766$.

Treisman, R., S.H. Orkin, and T. Maniatis. 1983. Specific transcription and RNA splicing defects in five cloned betathalassaemia genes. Nature 302: 591-596.

Ulfendahl, P.J., J.P. Kreivi, and G. Akusjarvi. 1989. Role of the branch site $/ 3^{\prime}$-splice site region in adenovirus-2 E1A premRNA alternative splicing: Evidence for $5^{\prime}$ - and $3^{\prime}$-splice site co-operation. Nucleic Acids Res. 17: 925-938.

Wang, L.H., S. Iijima, T. Dorai, and B. Lin. 1987. Regulation of the expression of proto-oncogene c-src by alternative RNA splicing in chicken skeletal muscle. Oncogene Res. 1: 4359.

Wu, J. and J.L. Manley. 1989. Mammalian pre-mRNA branch site selection by U2 snRNP involves base pairing. Genes \& Dev. 3: 1553-1561.

Yang, X.M. and G. Walter. 1988. Specific kinase activity and phosphorylation state of pp60c-src from neuroblastomas and fibroblasts. Oncogene 3: 237-244.

Zamore, P.D. and M.R. Green. 1989. Identification, purification, and biochemical characterization of U2 small nuclear ribonucleoprotein auxiliary factor. Proc. Natl. Acad. Sci. 86: 9243-9247.

Zhuang, Y. and A.M. Weiner. 1986. A compensatory base change in U1 snRNA suppresses a $5^{\prime}$ splice site mutation. Cell 46: 827-835.

- 1989. A compensatory base change in human U2 snRNA can suppress a branch site mutation. Genes \& Dev. 3: $1545-1552$.

Zillmann, M., S.D. Rose, and S.M. Berget. 1987. U1 small nuclear ribonucleoproteins are required early during spliceosome assembly. Mol. Cell. Biol. 7: 2877-2883. 


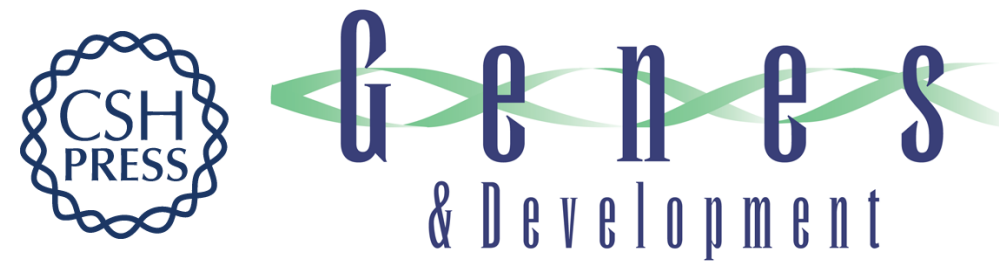

\section{Does steric interference between splice sites block the splicing of a short c-src neuron-specific exon in non-neuronal cells?}

D L Black

Genes Dev. 1991, 5:

Access the most recent version at doi:10.1101/gad.5.3.389

References This article cites 70 articles, 31 of which can be accessed free at:

http://genesdev.cshlp.org/content/5/3/389.full.html\#ref-list-1

License

Email Alerting

Service

Receive free email alerts when new articles cite this article - sign up in the box at the top right corner of the article or click here.

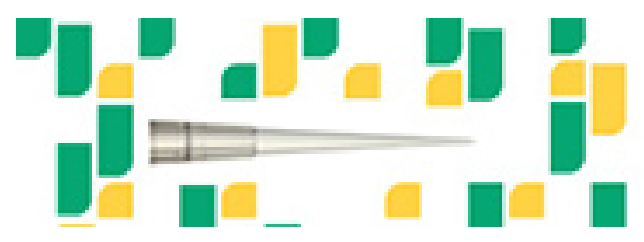

Focused on your science. 